\title{
Meta-analysis of defunctioning stoma in low anterior resection with total mesorectal excision for rectal cancer: evidence based on thirteen studies
}

Wen-long $\mathrm{Gu}^{1}$ and Sheng-wen $\mathrm{Wu}^{2^{*}}$

\begin{abstract}
Background: Recent studies have shown that a protective stoma can reduce morbidity in low anterior resection for rectal cancer; however, the necessity of it is still controversially discussed.

Methods: We performed this meta-analysis to provide a comprehensive evaluation of the role of defunctioning stoma in low anterior resection for rectal cancer on the rates of anastomotic leakage and reoperation related to leakage with or without defunctioning stoma by calculating the pooled risk ratio.

Results: Studies and relevant literature published between 2004 and 2014 regarding the construction of a protective stoma after low anterior resection were searched though PubMed and EMBASE databases. Finally, a total of 13 studies including 8,002 patients were included in this meta-analysis. The results indicated that protective stomas significantly reduced the rate of postoperative anastomotic leakage and reoperation after low anterior rectal resection. The pooled risk ratios were 0.47 (95\% Cl: 0.33-0.68, $P<0.0001)$ and 0.36 (95\% Cl: 028-0.46, $P<0.00001)$, respectively.

Conclusions: The findings from this present meta-analysis suggest that a defunctioning stoma could effectively reduce the clinical consequences of anastomotic leakage and reoperation, it is recommended in patients undergoing low rectal anterior resection for rectal cancer.
\end{abstract}

Keywords: Defunctioning stoma, Low anterior resection, Meta-analysis, Rectal cancer

\section{Background}

With better equipment and improved surgical techniques, low anterior resection with a low colorectal or coloanal anastomosis has become the technique of choice for rectal cancer, allowing a safe performance of anastomosis at a lower level in a way that the anal sphincter is saved [1]. Additionally, widespread propagation of standardized total mesorectal excision has improved overall survival [2]. However, total mesorectal excision may be associated with an increased risk of developing anastomotic leakage with attendant morbidity and mortality in the postoperative period [3]. Leaks may be associated with decreased local

\footnotetext{
*Correspondence: yxphpwk@163.com

${ }^{2}$ Department of General Surgery, The Affiliated Jianhu Hospital of Nantong University, Jianhu People's Hospital, Jianhu 224700, Jiangsu Province, China Full list of author information is available at the end of the article
}

control and survival $[4,5]$ and it is still one of the most fatal complications that occur after low anterior resection [6]. Even experienced surgeons sometimes find it difficult to predict which patient will have an anastomotic leak, and know that leaks may occur even when the anastomosis is technically sound and the risk factors for leakage are absent. When leakage ensues, it may increase morbidity, mortality, prolong the duration of hospital stay, and affect the short- or long-term quality of life $[7,8]$. Therefore, the rate of anastomotic leakage has been considered as one of the quality indicators of surgical performance.

Several retrospective or non-randomized prospective studies have shown that the absence of a protective stoma is a risk factor for leakage after low anterior resection [9], but others have disputed this [10]. Some surgeons use a protective stoma after low anterior resection to prevent 
the occurrence of anastomotic leak because it is believed that by diverting the fecal stream and keeping the anastomosis free of material, leakage will be less likely. While other surgeons reported that covering a protective stoma had no influence on anastomotic leak and reoperation rate, and the complications that can be caused by the stoma itself should not be ignored [11-17]. Although a defunctioning stoma is widely performed in low anterior resection for rectal cancer, it is still not clear whether protective stoma is useful for patients. Therefore, the role of defunctioning stoma in rectal cancer surgery is controversial. The primary aim of this meta-analysis was to evaluate the validity for low anterior resection with and without the creation of a defunctioning stoma.

\section{Methods}

Search strategy

Two bibliographic databases (PubMed and Embase) were searched for all relevant literature, including articles referenced in the publications. The medical subject headings $(\mathrm{MeSH})$ and keywords searched for individually and in combination were as follows: "stoma", "defunctioning stoma", "protective stoma", "low anterior resection", "rectal cancer", and "anastomotic leakage". The search ended in January $31^{\text {st }} 2014$, and no lower date limit was used. Bibliographies cited in an identified article were also searched manually to retrieve other suitable studies. We also screened the references of the relevant studies to check for potentially relevant articles.

\section{Inclusion and exclusion criteria}

Criteria for eligibility of a study included in this metaanalysis were i) studies that compared low anterior resection with or without a protective stoma; ii) recent clinical trials from 2004 to 2014. When a study reporting the same patient cohort was included in several publications, only the most recent or complete study was selected. Exclusion criteria included i) case reports, letters, and reviews without original data; ii) non-English papers; iii) animal or laboratory studies; or iv) articles that were not full-text and non-comparative studies. To avoid the influence of redundant studies, we checked all of the authors and organizations, and evaluated the accrual period and community of patients enrolled for each study.

\section{Data extraction}

Extracted data were crosschecked between the two authors to rule out any discrepancy. The following data was independently extracted for each included study: first author's surname, publication year, sample size, and the number of patients that developed an anastomotic leak and needed a reoperation related to leakage after low anterior resection with or without protective stoma. Disagreements were discussed by the authors and resolved by consensus.

\section{Statistical analysis}

Statistical analysis was carried out using the Review Manager 5.2. A pooled risk ratio (RR) with $95 \%$ confidence intervals (CIs) was used to assess outcomes of the studies. $I^{2}$ statistics was used to evaluate the betweenstudy heterogeneity analysis in this meta-analysis [18]. The random effects model was used when an obvious heterogeneity was observed among the included studies $\left(I^{2}>50 \%\right)$. The fixed effects model was used when there was no significant heterogeneity between the included studies $\left(I^{2} \leq 50 \%\right)$. Publication bias was estimated using a funnel plot with an Egger's linear regression test; funnel plot asymmetry on the natural logarithm scale of the RR was measured by a linear regression approach.

\section{Ethical standards}

This study complies with current laws of china.

\section{Results \\ Eligible studies}

In total, 13 studies were included in the meta-analysis [19-31], all of which were published between 2004 and 2014. There were four randomized controlled trials $[20,26,27,31]$ and nine non-randomized studies with a total population of 8,002 patients, of whom 3,562 had a protective stoma and 4,440 did not. The sample size of the trials ranged from 34 to 1,958 . All studies reported the number of patients who developed an anastomotic leak and required a reoperation after low anterior resection or ultralow anterior resection. Table 1 lists the main characteristics of the 13 studies included in this analysis.

\section{Meta-analysis}

There was obvious between-study heterogeneity among the 13 included studies $\left(\mathrm{I}^{2}=61 \%\right)$, thus the random effects model was used to calculate the pooled RRs with corresponding 95\% CIs. The present meta-analysis demonstrated that the absence of a protective stoma was associated with a higher incidence of anastomotic leak and reoperation, with pooled RRs of 0.47 (95\% CI: $0.33-$ $0.68, P<0.0001$, Figure 1 ) and 0.36 (95\% CI: 028-0.46, $P<0.00001$, Figure 2), respectively. This revealed that a statistically significant advantage was conferred by a protective stoma in patients undergoing low anterior resection.

\section{Publication bias}

Funnel plot and Egger's test were used to evaluate the publication bias of the included studies. The shape of the funnel plot for the meta-analysis of studies on 
Table 1 Main characteristics of the 13 included studies

\begin{tabular}{|c|c|c|c|c|c|c|c|c|c|}
\hline \multirow[b]{2}{*}{ Author } & \multirow[b]{2}{*}{ Year } & \multirow[b]{2}{*}{ No. of patients } & \multicolumn{2}{|l|}{$\mathbf{N}$} & \multirow[b]{2}{*}{ Type of operation } & \multicolumn{2}{|c|}{ Leakage } & \multicolumn{2}{|c|}{ Reoperation } \\
\hline & & & Stoma & No stoma & & Stoma & No stoma & Stoma & No stoma \\
\hline Beirens et al. [19] & 2012 & 1,912 & 1,183 & 729 & LAR & 51 & 74 & 40 & 69 \\
\hline Chude et al. [20] & 2008 & 256 & 136 & 120 & LAR & 3 & 12 & 0 & 2 \\
\hline Eriksen et al. [21] & 2005 & 1,958 & 622 & 1,336 & LAR & 64 & 164 & NA & NA \\
\hline Gong et al. [22] & 2012 & 62 & 36 & 26 & ULAR & 0 & 5 & 0 & 2 \\
\hline Karahasanogl et al. [23] & 2011 & 77 & 23 & 54 & LAR & 0 & 3 & NA & NA \\
\hline Lefebure et al. [24] & 2008 & 132 & 42 & 90 & LAR & 3 & 10 & 1 & 5 \\
\hline Ma et al. [25] & 2013 & 56 & 30 & 26 & LAR & 2 & 7 & 0 & 5 \\
\hline Matthiessen et al. [26] & 2004 & 432 & 72 & 360 & LAR & 11 & 42 & 1 & 32 \\
\hline Matthiessenet al. [27] & 2007 & 234 & 116 & 118 & LAR & 12 & 33 & 12 & 32 \\
\hline Nurkin et al. [28] & 2013 & 1,791 & 958 & 833 & LAR & 17 & 26 & 37 & 63 \\
\hline Seo et al. [29] & 2013 & 836 & 246 & 590 & ULAR & 1 & 22 & NA & NA \\
\hline Shiomi et al. [30] & 2010 & 222 & 80 & 142 & LAR & 3 & 17 & 0 & 14 \\
\hline Ulrich et al. [31] & 2009 & 34 & 18 & 16 & LAR & 1 & 6 & 0 & 6 \\
\hline
\end{tabular}

LAR, Low anterior resection; uLAR, Ultralow anterior resection; NA, Not applicable.

postoperative anastomotic leakage demonstrated obvious asymmetry (Figure 3).

\section{Discussion}

With the development of rectal cancer and the improvement of medical instruments, together with higher requirements by patients for the quality of post-surgical life, ultralow anterior rectal resection has become the major low sphincter preserving procedure. However, this procedure can also increase the risk of anastomotic leakage [9].

The occurrence of adverse intraoperative events was identified as an important risk factor, as previously been indicated by Matthiessen et al. [26]. Moreover, a long operation time and major perioperative bleeding are inter-correlated factors previously discussed in other studies as both single [32] and combined [33] risk factors. Preoperative radiotherapy appeared to be a predisposing factor for leakage in earlier studies of consecutive cases [34]. In addition to the already known risk factors, such as male gender and low anastomoses, other risk factors, such as type of anastomosis and intra-abdominal drainage, have also been identified. Jestin et al. [35] observed that adverse intraoperative events, a long duration of surgery, and major bleeding, all of which are indicators of complicated surgery, increase the risk of leakage. When these occur, the events have been associated with both reduced disease-free survival and overall survival rates.

Defunctioning stoma in low anterior resection has been considered to decrease the leakage rate and its fatal consequences. However, the value of a protective stoma has been the subject of controversy for many years. In previous publications, overall leakage and reoperation rates have been shown to be similar in patients with or without a protective stoma [36]. In addition, ostomy construction and closure is associated with considerable morbidity and increased costs [37]. Potential disadvantages of a protective stoma include the need for

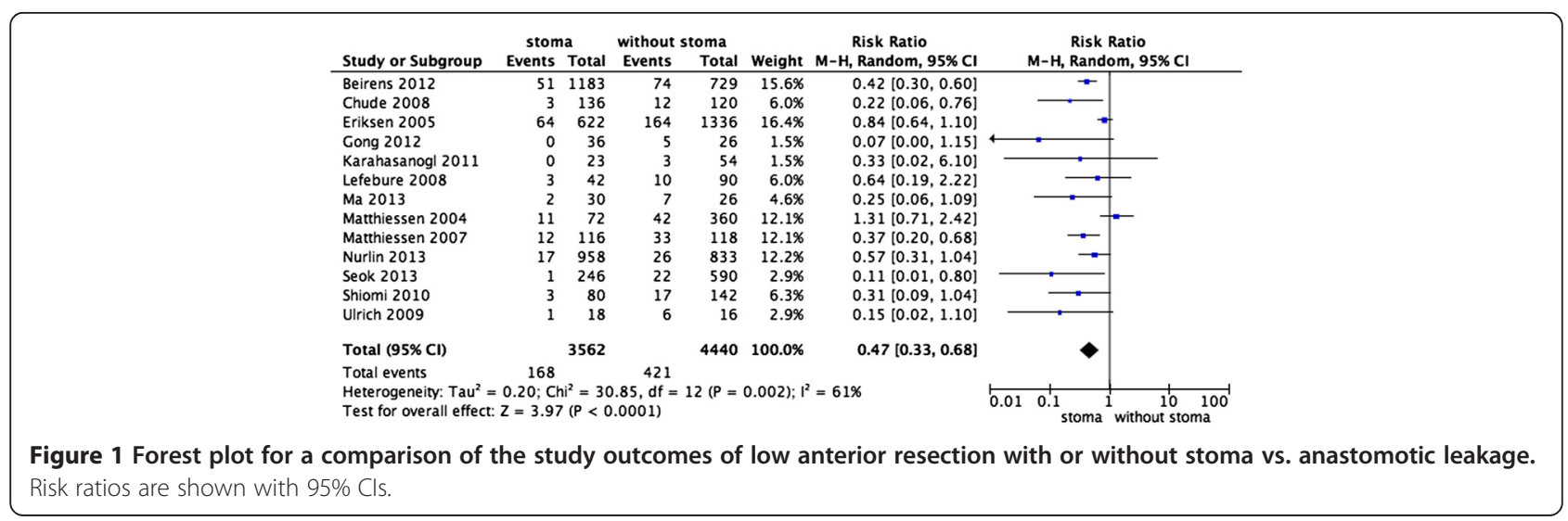




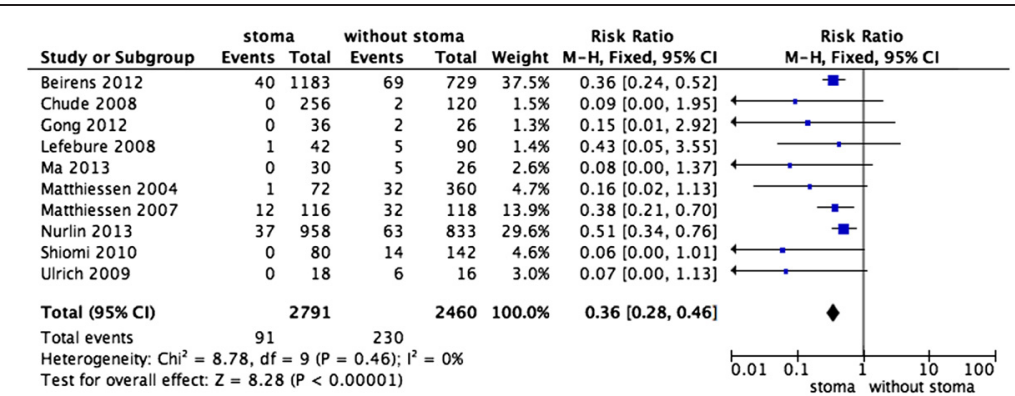

Figure 2 Forest plot of the study outcomes of low anterior resection with or without stoma vs. reoperation rate. Risk ratios are shown with $95 \% \mathrm{Cls}$.

re-operation, longer hospital stay, and ostomy-related complications, such as dehydration, which could prove fatal. Therefore, the benefits of a protective stoma in decreasing the rate of anastomotic leakage have to be balanced against the morbidity of its construction and closure [38]. Nevertheless, the benefits conferred by a protective stoma have not been unequivocally demonstrated. To further evaluate this argument, we performed the present meta-analysis. The straightforward conclusion from the 13 included studies was that a protective stoma after a low anterior resection significantly reduces the rate of anastomotic leakage and the number of reoperations related to leakage.

However, we still should regard these outcomes with caution and evaluate them critically for the following reasons. Firstly, funnel plots were performed to evaluate publication bias. The shape of the funnel plot for the meta-analysis of studies on postoperative anastomotic leakage demonstrated obvious asymmetry in their results. We interpreted this asymmetry as different case selection, such as elective or emergency low anterior resection for rectal cancer. Due to the limitations in terms of medical ethics, not all of the trials were randomized controlled trials and the sample size in some studies was rather low, rendering the overall methodological quality and reporting of the included studies rather poor. Secondly, considerable selection bias existed in some of the included studies. Surgeons relied on their personal experience to predict the patients who were at high risk of an anastomotic leakage, which may have been inaccurate, leading to a selection bias of those who underwent stoma formation. Thirdly, the original purpose of the defunctioning stoma was to minimize the rate of anastomotic leakage, but morbidity and mortality can occur at the time of stoma closure. Furthermore, patients who received a protective stoma require readmission for the stoma closure [16].

\section{Conclusions}

In conclusion, despite the inherent limitations of metaanalysis on stoma literature, this meta-analysis, representing a quantified synthesis of all published studies of protective stoma, has shown that a defunctioning stoma significantly reduces the rate of anastomotic leakage and

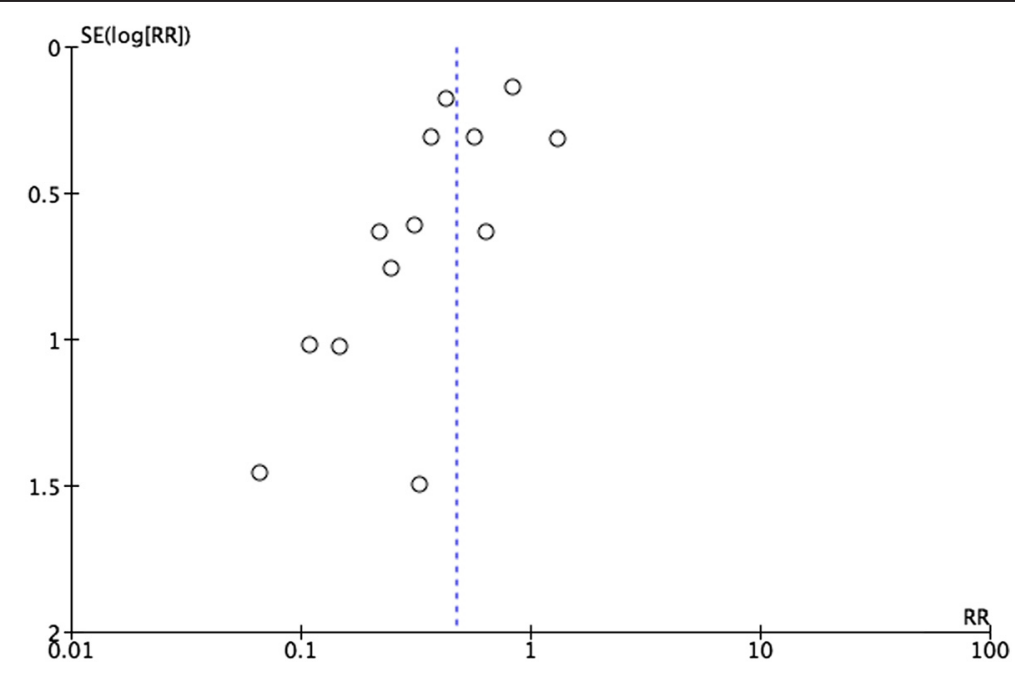

Figure 3 Funnel plot for the publication bias. 
reoperation in patients that receive low anterior resection for rectal cancer. Morbidity associated with protective stoma and complications of stoma closure are negligible compared to the reoperations required for anastomotic leakage in the absence of protective stoma. Therefore, a defunctioning stoma can be useful for patients undergoing rectal surgery, and is recommended during a low anterior resection for rectal cancer.

\section{Consent}

Written informed consent was obtained from the patients for the publication of this report and any accompanying images.

\section{Abbreviations}

Cls: Confidence intervals; RR: Risk ratio.

\section{Competing interests}

The authors declare that they have no competing interests.

\section{Authors' contributions}

WLG carried out data analysis and wrote the manuscript; SWW and WLG identified and acquired reports of trials, abstracted the data and assessed the risk of bias; SWW conducted the statistical analyses and contacted authors of included studies to obtain additional information; SWW drafted the manuscript; Both authors read and approved the final manuscript.

\section{Author details}

${ }^{1}$ Department of Medical Oncology, The Affiliated Jianhu Hospital of Nantong University, Jianhu People's Hospital, Jianhu 224700, Jiangsu Province, China. ${ }^{2}$ Department of General Surgery, The Affiliated Jianhu Hospital of Nantong University, Jianhu People's Hospital, Jianhu 224700, Jiangsu Province, China.

Received: 13 May 2014 Accepted: 23 December 2014

Published online: 24 January 2015

\section{References}

1. Griffen FD, Knight Sr CD, Whitaker JM, Knight Jr CD. The double stapling technique for low anterior resection. Results, modifications, and observations. Ann Surg. 1990;211:745-51. Discussion 751-2.

2. Kapiteijn E, Putter $\mathrm{H}$, van de Velde CJ, Cooperative investigators of the Dutch ColoRectal Cancer Group. Impact of the introduction and training of total mesorectal excision on recurrence and survival in rectal cancer in The Netherlands. Br J Surg. 2002;89:1142-9.

3. den Dulk M, Noter SL, Hendriks ER, Brouwers MA, van der Vlies $\mathrm{CH}$, Oostenbroek RJ, et al. Improved diagnosis and treatment of anastomotic leakage after colorectal surgery. Eur J Surg Oncol. 2009;35:420-6.

4. Law WL, Choi HK, Lee YM, Ho JW, Seto CL. Anastomotic leakage is associated with poor long-term outcome in patients after curative colorectal resection for malignancy. J Gastrointest Surg. 2007;11:8-15.

5. Ptok H, Marusch F, Meyer F, Schubert D, Gastinger I, Lippert H, et al. Impact of anastomotic leakage on oncological outcome after rectal cancer resection. Br J Surg. 2007;94:1548-54.

6. Rahbari NN, Weitz J, Hohenberger W, Heald RJ, Moran B, Ulrich A, et al. Definition and grading of anastomotic leakage following anterior resection of the rectum: a proposal by the International Study Group of Rectal Cancer. Surgery. 2010;147:339-51.

7. Nesbakken A, Nygaard K, Lunde OC. Outcome and late functional results after anastomotic leakage following mesorectal excision for rectal cancer. Br J Surg. 2001;88:400-4.

8. McArdle CS, McMillan DC, Hole DJ. Impact of anastomotic leakage on long-term survival of patients undergoing curative resection for colorectal cancer. Br J Surg. 2005:92:1150-4.

9. Peeters KC, Tollenaar RA, Marijnen CA, Klein Kranenbarg E, Steup WH, Wiggers $\mathrm{T}$, et al. Risk factors for anastomotic failure after total mesorectal excision of rectal cancer. Br J Surg. 2005;92:211-6.
10. Wong NY, Eu KW. A defunctioning ileostomy does not prevent clinical anastomotic leak after a low anterior resection: a prospective, comparative study. Dis Colon Rectum. 2005;48:2076-9.

11. Law WL, Chu KW, Choi HK. Randomized clinical trial comparing loop ileostomy and loop transverse colostomy for faecal diversion following total mesorectal excision. Br J Surg. 2002;89:704-8.

12. Hallbook $O$, Matthiessen $P$, Leinskold T, Nystrom PO, Sjodahl R. Safety of the temporary loop ileostomy. Colorectal Dis. 2002;4:361-4.

13. Bakx R, Busch OR, Bemelman WA, Veldink GJ, Slors JF, van Lanschot JJ. Morbidity of temporary loop ileostomies. Dig Surg. 2004;21:277-81.

14. Laurent C, Nobili S, Rullier A, Vendrely V, Saric J, Rullier E. Efforts to improve local control in rectal cancer compromise survival by the potential morbidity of optimal mesorectal excision. J Am Coll Surg. 2006;203:684-91.

15. Kaiser AM, Israelit $S$, Klaristenfeld D, Selvindoss $P$, Vukasin $P$, Ault $G$, et al. Morbidity of ostomy takedown. J Gastrointest Surg. 2008;12:437-41.

16. van Westreenen HL, Visser A, Tanis PJ, Bemelman WA. Morbidity related to defunctioning ileostomy closure after ileal pouch-anal anastomosis and low colonic anastomosis. Int J Colorectal Dis. 2012;27:49-54.

17. Cipe G, Erkek B, Kuzu A, Gecim E. Morbidity and mortality after the closure of a protective loop ileostomy: analysis of possible predictors. Hepatogastroenterology. 2012;59:2168-72.

18. Higgins JP, Thompson SG, Deeks JJ, Altman DG. Measuring inconsistency in meta-analyses. BMJ. 2003;327:557-60.

19. Beirens K, Penninckx F. Procare: defunctioning stoma and anastomotic leak rate after total mesorectal excision with coloanal anastomosis in the context of Procare. Acta Chir Belg. 2012;112:10-4.

20. Chude GG, Rayate NV, Patris V, Koshariya M, Jagad R, Kawamoto J, et al. Defunctioning loop ileostomy with low anterior resection for distal rectal cancer: should we make an ileostomy as a routine procedure? A prospective randomized study. Hepatogastroenterology. 2008;55:1562-7.

21. Eriksen MT, Wibe A, Norstein J, Haffner J, Wiig JN, Norwegian Rectal Cancer Group. Anastomotic leakage following routine mesorectal excision for rectal cancer in a national cohort of patients. Colorectal Dis. 2005;7:51-7.

22. Gong $H, Y u$ Y, Yao Y. Clinical value of preventative ileostomy following ultra-low anterior rectal resection. Cell Biochem Biophys. 2013;65:491-3.

23. Karahasanoglu T, Hamzaoglu I, Baca B, Aytac E, Erenler I, Erdamar S. Evaluation of diverting ileostomy in laparoscopic low anterior resection for rectal cancer. Asian J Surg. 2011;34:63-8.

24. Lefebure B, Tuech JJ, Bridoux V, Costaglioli B, Scotte M, Teniere P, et al. Evaluation of selective defunctioning stoma after low anterior resection for rectal cancer. Int J Colorectal Dis. 2008;23:283-8.

25. Ma CC, Wu SW. Retrospective analysis of protective stoma after low anterior resection for rectal cancer with total mesorectal excision: three-year follow-up results. Hepatogastroenterology. 2013:60:420-4.

26. Matthiessen P, Hallbook O, Andersson M, Rutegard J, Sjodahl R. Risk factors for anastomotic leakage after anterior resection of the rectum. Colorectal Dis. 2004:6:462-9.

27. Matthiessen P, Hallbook O, Rutegard J, Simert G, Sjodahl R. Defunctioning stoma reduces symptomatic anastomotic leakage after low anterior resection of the rectum for cancer: a randomized multicenter trial. Ann Surg. 2007;246:207-14

28. Nurkin S, Kakarla VR, Ruiz DE, Cance WG, Tiszenkel HI. The role of faecal diversion in low rectal cancer: a review of 1791 patients having rectal resection with anastomosis for cancer, with and without a proximal stoma. Colorectal Dis. 2013;15:e309-16.

29. Seo SI, Yu CS, Kim GS, Lee JL, Yoon YS, Kim CW, et al. The role of diverting stoma after an ultra-low anterior resection for rectal cancer. Ann Coloproctol. 2013:29:66-71.

30. Shiomi A, Ito M, Saito N, Hirai T, Ohue M, Kubo Y, et al. The indications for a diverting stoma in low anterior resection for rectal cancer: a prospective multicentre study of 222 patients from Japanese cancer centers. Colorectal Dis. 2011:13:1384-9.

31. Ulrich AB, Seiler C, Rahbari N, Weitz J, Buchler MW. Diverting stoma after low anterior resection: more arguments in favor. Dis Colon Rectum. 2009;52:412-8

32. Marusch F, Koch A, Schmidt U, Geibetaler S, Dralle H, Saeger HD, et al. Value of a protective stoma in low anterior resections for rectal cancer. Dis Colon Rectum. 2002:45:1164-71.

33. Makela JT, Kiviniemi H, Laitinen S. Risk factors for anastomotic leakage after left-sided colorectal resection with rectal anastomosis. Dis Colon Rectum. 2003;46:653-60. 
34. Poon RT, Chu KW, Ho JW, Chan CW, Law WL, Wong J. Prospective evaluation of selective defunctioning stoma for low anterior resection with total mesorectal excision. World J Surg. 1999;23:463-7. Discussion 467-468

35. Jestin P, Pahlman L, Gunnarsson U. Risk factors for anastomotic leakage after rectal cancer surgery: a case-control study. Colorectal Dis. 2008;10:715-21.

36. Gastinger I, Marusch F, Steinert R, Wolff S, Koeckerling F, Lippert H, et al. Protective defunctioning stoma in low anterior resection for rectal carcinoma. Br J Surg. 2005;92:1137-42.

37. Tsunoda A, Tsunoda Y, Narita K, Watanabe M, Nakao K, Kusano M. Quality of life after low anterior resection and temporary loop ileostomy. Dis Colon Rectum. 2008;51:218-22.

38. Pakkastie TE, Ovaska JT, Pekkala ES, Luukkonen PE, Jarvinen HJ. A randomised study of colostomies in low colorectal anastomoses. Eur J Surg. 1997;163:929-33.

\section{Submit your next manuscript to BioMed Central and take full advantage of:}

- Convenient online submission

- Thorough peer review

- No space constraints or color figure charges

- Immediate publication on acceptance

- Inclusion in PubMed, CAS, Scopus and Google Scholar

- Research which is freely available for redistribution 